\title{
Toxicological evaluation of tannery industry waste water on Oreochromis mossambicus
}

\author{
P. S. Navaraj ${ }^{\star}$ and J. Yasmin \\ Department of Zoology, Yadava College, Madurai, India. \\ Accepted 18 July, 2012
}

\begin{abstract}
This paper investigates the impact of tannery industry wastewater on 0 . mossambicus. The histopathological changes observed in gills, liver, kidney and brain of the studied fish have demonstrated the quality status of industrial waste water. In the vital organs, the following marked changes were observed: filament cell proliferation, cellular infiltration, haemorrhage and epithelial lifting in gills, vacuolation of hepatocytes and necrosis in liver, exfoliation and swollen with pyknotic nuclei in kidney and enlarged pyramidal cells, binucleated nuclei, vacuolation, and necrosis in brain. These changes might be due to the various components of tannery wastewater on fish. Hence, proper treatment of tannery industry wastewater is highly recommended through this study.
\end{abstract}

Key words: Oreochromis mossambicus, acute toxicity, histopathology, tannery mill wastewater, liver, gills, kidney, brain.

\section{INTRODUCTION}

The tannery industry has shown tremendous expansion during the last 25 years. However, the tannery industry adds pollutants to the aquatic environment. The tannery mill industry wastewater consists of variety of toxic components such as heavy metals, soda, lignin, chlorine, resin acid, dioxin, furan etc, which might be responsible for inducing histochemical changes in Rasbora daniconius (Pathan et al., 2009). Srivastava et al. (2007) also confirmed that 1 to $10 \%$ of tannery wastewaters kill fish. The tannery wastewaters continue to cause negative effects in aquatic organisms as they also have endocrine disruption effects (Hewitt et al., 2006).

Biological changes in fish caused due to the exposure of contaminants are called biomarkers that can be used for environmental risk assessment (Van der Oost et al., 2003). Physiological and biochemical parameters as indicators of water quality were used to detect sub-lethal impacts of pollutants. Prominent among these biomarkers are haematological data (Lohner et al., 2001; and physiological variables, such as plasma levels of metabolites (Ebeling, 1931) and ions (Kohler, 2002), levels of hormones like cortisol (Walden, 1976) and

\footnotetext{
*Corresponding author: E-mail: navaraj678@sify.com.
}

biochemical variables such as detoxifying enzyme activities (Pugazhvendan et al., 2009).

Histopathological changes have also been widely used as biomarkers in the evaluation of the health of fish exposed to contaminants, both in laboratory (Van Horn, 1961) and in field studies (Das and Mukherjee, 2000). One of the advantages of using histopathological biomarkers in environmental monitoring is that this category of biomarkers allows examining specific target organs including gills, liver, kidney, brain that are responsible for vital functions, such as respiration, detoxification, excretion and coordination.

Likewise, accumulation and biotransformation of xenobiotics in fish (Hewitt et al., 2006) can also be ascertained through this. Furthermore, the alteration found in organs would assist in identifying its functional status (Fanta et al., 2003) and providing warning signs of damage (Pandey et al., 2008) to animal health. Tannery industry wastewater is released into the aquatic habitat without any proper treatment. This would be a major environmental threat in Dindigul and Madurai Districts.

Hence, there is a need to project the toxic status of tannery waste water to the public. Therefore, this study has been carried out to understand the status of gill, liver, kidney and brain tissues of Oreochromis mossambicus exposed to tannery industry wastewater. This will project 
Table 1. Physico-chemical characteristic features of tannery industry wastewater.

\begin{tabular}{clllc}
\hline S. no & Parameter & Unit & Values & BIS \\
\hline 1 & Colour & - & Dark brown & - \\
2 & Smell & - & Unpleasant & - \\
3 & pH & - & 8.05 & - \\
4 & Electrical conductivity & Micromhos/cm & 12,700 & - \\
5 & Total dissolved solids & ppm & 20400 & 500 \\
6 & Total harness & ppm & 2210 & 300 \\
7 & Alkalinity & ppm & 225 & 200 \\
8 & Chloride & ppm & 12750 & 250 \\
9 & Dissolved oxygen & ppm & 4.7 & $5-6$ \\
10 & BOD & ppm & 74 & 30 \\
11 & COD & ppm & 530 & 25 \\
12 & Sodium & ppm & 1275 & 5 \\
13 & Potassium & ppm & 76 & 5 \\
14 & Total Chromium & ppm & 1.0 & 0.05 \\
\hline
\end{tabular}

the impact of tannery industry waste water on aquatic animals.

\section{MATERIALS AND METHODS}

The adult Mozambique tilapias, 0 . mossambicus (30 to $40 \mathrm{~g}$ b.w.) comprising both sexes were collected from local fish market and fed once a day with $1 \%$ b.w. commercial fish feed. Fish were acclimatized in laboratory condition for two weeks at a water temperature of $28 \pm 1^{\circ} \mathrm{C}$ before the commencement of the experiment.

The wastewater collected from tannery industry in Dindigul was transported and preserved. This sample was used throughout the experimental period. The $\mathrm{LC}_{50}$ value of tannery mill wastewater was analysed through a static renewal bioassay technique. Preliminary screening was carried out to determine the appropriate concentration range for testing chemical as described by Solbe (1995). 1, 4, 7 and $10 \%$ concentrations of tannery mill wastewater were used with 3 replicates each for $96 \mathrm{~h}$ bioassay through probit analysis. Ten fish were used in each aquarium containing the selected waste water concentrations as well as in control. The $\mathrm{LC}_{50}$ value was estimated at $7 \%$ concentration, and subsequently, sublethal concentrations, $0.8,1,1.2$ and $1.4 \%$ of wastewater was selected.

Ten fishes were exposed to sub-lethal concentrations of waste water for two months. Simultaneously, a control group was also maintained. The experimental set up is maintained promptly with the renewal of wastewater daily, and feed was given daily ad libitum. After the duration of experiment ( 60 days), fish were taken from the respective concentrations and subsequently the vital organs (gill, liver, kidney and brain) were removed by live dissection and fixed in Davidson fluid for $24 \mathrm{~h}$.

Then organ tissues were washed with $70 \%$ ethanol and dehydrated through a graded series of ethanol (Schalm et al., 1995; Kelly, 1979). Subsequently, the tissues were embedded in paraffin, sectioned at 4 to $5 \mathrm{~mm}$ thickness, stained with haematoxylin and eosin and finally examined under photomicrography (Kaneko, 1989).

\section{RESULT}

The physico-chemical characteristic features of tannery industry waste water have demonstrated that components have crossed the BIS limit (Table 1).

\section{Bioassay}

No adverse behavioural changes, color changes or mortality was recorded in the control fish throughout the period of the bioassay. Symptoms of toxicosis observed in fish exposed to wastewater include lack of balance, agitated or erratic swimming, air gulping and restlessness, sudden quick movement, excessive section of mucus, rolling movement and swimming on the back were observed.

The fish became very weak, settled at the bottom and died. Likewise, the colour of the skin of $O$. mossambicus changes from normal dark pigmentation to very light pigmentation in the dorsal and lateral part. The $\mathrm{LC}_{50}$ value was found to be 12, 10,8 and $7 \%$ for $24,48,72$ and $96 \mathrm{~h}$, respectively (Figure 1).

\section{Histopathological studies}

\section{Gills}

The primary lamellae of the gills, projecting from the gill arch appear like the teeth of a comb. The semi lunar fold found in one or two cell layer thickened primary lamellae increases its surface area. At the base of the secondary lamella, chloride cells where identified with light cytoplasm. Two sheets of epithelium, which makes up the secondary lamellae was delimited by many pillar cells. One or two erythrocytes were usually observed within each capillary lumen. No recognizable changes were observed in the control gills (Figure 2a). But in the experimental fish, typical chronic changes occurred in 


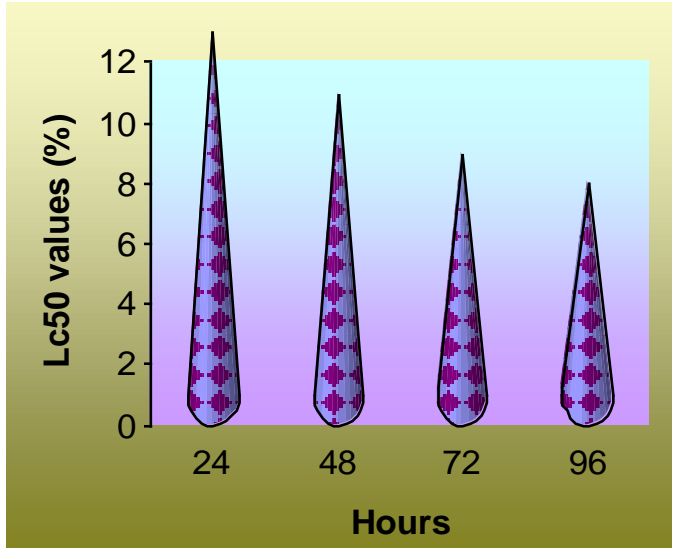

Figure 1. LC50 values of tannery wastewater against $O$. mossambicus at different durations.

gills surface; hyperplasia, epithelial lifting, cell swellings congestions, the bending of secondary lamellae, formation of oedematous space between the layers of epithelium which may become infiltrated with red blood cells and leukocytes (Figure $2 b$ to d). Finally, hyper-plasic tissues were observed in the primary epithelial cells. Then, the whole epithelium became degenerated and the lamella lost its rigidity (Figure $2 \mathrm{e}$ )

\section{Liver}

The histology of control fish liver revealed normal typical paranchymatous appearance. The liver was made up of hepatocytes that were polygonal cells with a central spherical nucleus and a densely stained nucleolus (Figure 3a). The histological study revealed glycogen vacuolation, fatty infiltration, hemosiderosis and congested central vein at the lowest concentration $(0.8 \%)$ of wastewater. But, a severe infiltration of leukocytes, pyknotic nuclei and hepatic necrosis were observed at the highest concentration (1.4\%) of the wastewater (Figure $3 b$ to e).

\section{Kidney}

The control kidney (Figure 4a) shows perfect nephrons with interstitial lymphoid tissue. The renal corpuscles and renal tubules are intact. The cluster of capillaries (glomerulus) surrounded by Bowman's capsule and the endothelial cell covering glomerulus were in normal condition. When the fish is exposed to tannery mill wastewater, kidney exhibited enlarged sinusoids within an apparently decreased amount of haematopoietic tissue (Figure 4b). Interestingly, nephrons showed occluded glomerular capillaries and separation of the renal tubular epithelium from the surrounding connective tissue (Figure 4c). Necrosis was also observed in hematopoietic tissue, glomerular cells, and tubular cell as well as eosinophilic exudates in glomerulus (Figure $4 d$ and e).

\section{Brain}

There is no any significant lesion in control fish (Figure 5a). Histological study of the brain of fish exposed to $0.8 \%$ wastewater showed enlargement of pyramid nuclear formation (Figure $5 b$ ). When fish were exposed to $1.0 \%$ wastewater, swelling of pyramidal cells with binucleated nuclei (bn) (Figure 5c) was noted. A severe necrosis (Figure 5d), and vacuolar changes with empty spaces at 1.2 and $1.4 \%$ (Figure $5 \mathrm{e}$ ) exposures respectively were identified.

\section{DISCUSSION}

The present study shows $96 \mathrm{~h} \mathrm{LC} \mathrm{L}_{50}$ value of tannery mill wastewater, $7 \%$ to 0 . mossambicus and this value is duration dependent. Varadaraj and Subramanian (1991) reported $\mathrm{LC}_{50}$ value as $8 \%$ for $96 \mathrm{~h}$ tannery industry wastewater toxicity to fingerlings of 0 . mossambicus. Similarly, Rajendra et al. (1991) reported LC $_{50}$ value as $16.5 \%$ for $96 \mathrm{~h}$ tannery wastewater toxicity to fish Puntius sophor; and Nanda et al. (2002) demonstrated LC 50 values at 9.3, 10.3 and $12.6 \%$ for Anabus testudineus, Channa punctatus and Clarias batrachus, respectively. This indicates that $O$. mossambicus is most sensitive and susceptible to tannery mill wastewater toxicity.

Histopathological study of gills showed lamellar cell hyperplasia, epithelial lifting, lamellar fusion and edema. Similar observation such as the damages of gills indicates impairment in gaseous exchange efficiency in fish. The observation of oedematous of the lamella and hyperplasia in this work are quite similar to the work of Srivastava (2007). The stressful behaviour of respiratory impairment due to the toxic effect of zinc, one of the main components of tannery wastewater on C. punctata (Helmlata and Srivastava, 2008) and Labio rohita (Loganathan et al., 2006), adds support to this finding. The infiltration of components of tannery wastewater through the gills might have caused these abnormalities.

The histological observation indicated some alteration in liver parenchyma, such as blood congestion in sinusoids, vacuolation of hepatocytes and necrosis. Many reports revealed a variety of changes in the liver of Oreochromis niloticus, resulting from exposure to different toxic chemicals (Figueiredo-Fernandes et al., 2007). Mario et al. (2010) revealed that the Bleached Kraft paper mill wastewater caused histological changes in the hepatic tissue of both Carassius auratus and Dicentrarchus labrax. However, the results suggest that the tannery mill wastewater was more toxic for $O$. mossambicus since necrosis and proliferative lesions 


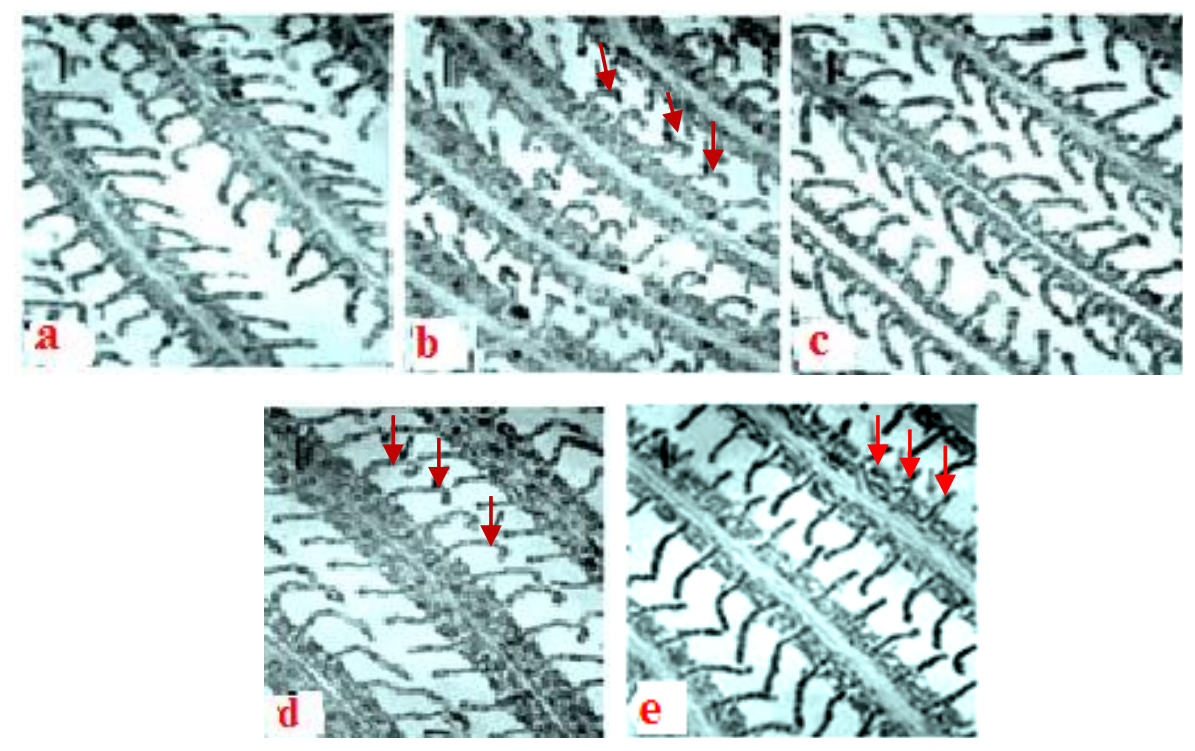

Figure 2. Light micrographs of gill of $O$. mossambicus in (a) control group showing normal arrangement of primary and secondary lamella, (b to e) bending of the distal extremities of secondary lamellae and epithelial lifting.
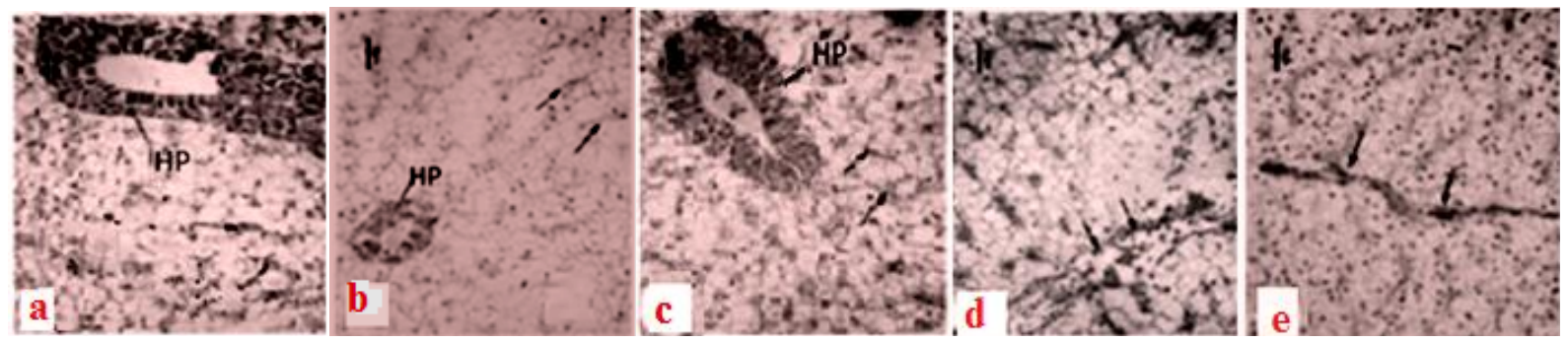

Figure 3. Light micrographs of liver of $O$. mossambicus. (a) Control group showing normal hepatocytes and blood sinusoids; (b to e) group showing vacuolation, infiltration, and hepatic necrosis.

were observed. Hepatic alterations such as hepatocellular and nuclear polymorphism, multicellular hypertrophy and necrosis supported the findings and Olojo et al. (2005) in metal contaminated ecosystem. The toxic impurities can easily reach the liver; hence this damage is possible in animals.

The kidney is an organ of excretion. The toxic impurities present in the filterate will affect the structure of organ itself. The histological changes observed in kidney include shrinkage, destruction of tubular epithelium, vacuolarization and damage of glomerulus. The renal corpuscles of the kidney were scattered resulting in their disorganization and consequently obstruction to their physiological functions. Some of the kidney cells were found clogging together while they were disintegrated in some tissues of the organ. This also agreed with the findings of Rahman et al. (2002). Similar findings such as dilation of the lumina of the kidney tubules, necrosis of tubules, shrinkage of glomerular tuft and vacuolation of blood cells in the glomerular tuft have been reported in
Heteropneustes fossilis exposed to chlorpyrifos (Srivastava et al., 2007) and in Rasbora daniconius exposed to industrial wastewater (Pathan et al., 2009). Interestingly, Elsan treatment in $C$. punctatus resulted in a significant decrease in the dimension of Bowman's capsule and glomerulus, and the tubules lost their regular shape due to precipitation of cytoplasm and karyolysis (Varadaraj, 1991); this has strongly defended the findings of this study.

In the present study, fish brain receives the toxic components through blood carrier. The histological changes in fish brain shows swelling of pyramidal cells, binucleated nuclei, vacuolation. Similar changes were observed by Das and Mukherjee (2000) in Labeo rohita exposed to pesticides, wastewater and chemicals like hexa chloro cyclohexane. Likewise, Ayoola and Ajani (2008) found out severe congestion and generalised spongiosis in brain of fish exposed to cypermethrine. This agrees with the findings of severe necrosis in the brain of fish exposed to zinc (Loganathan et al., 2006). 

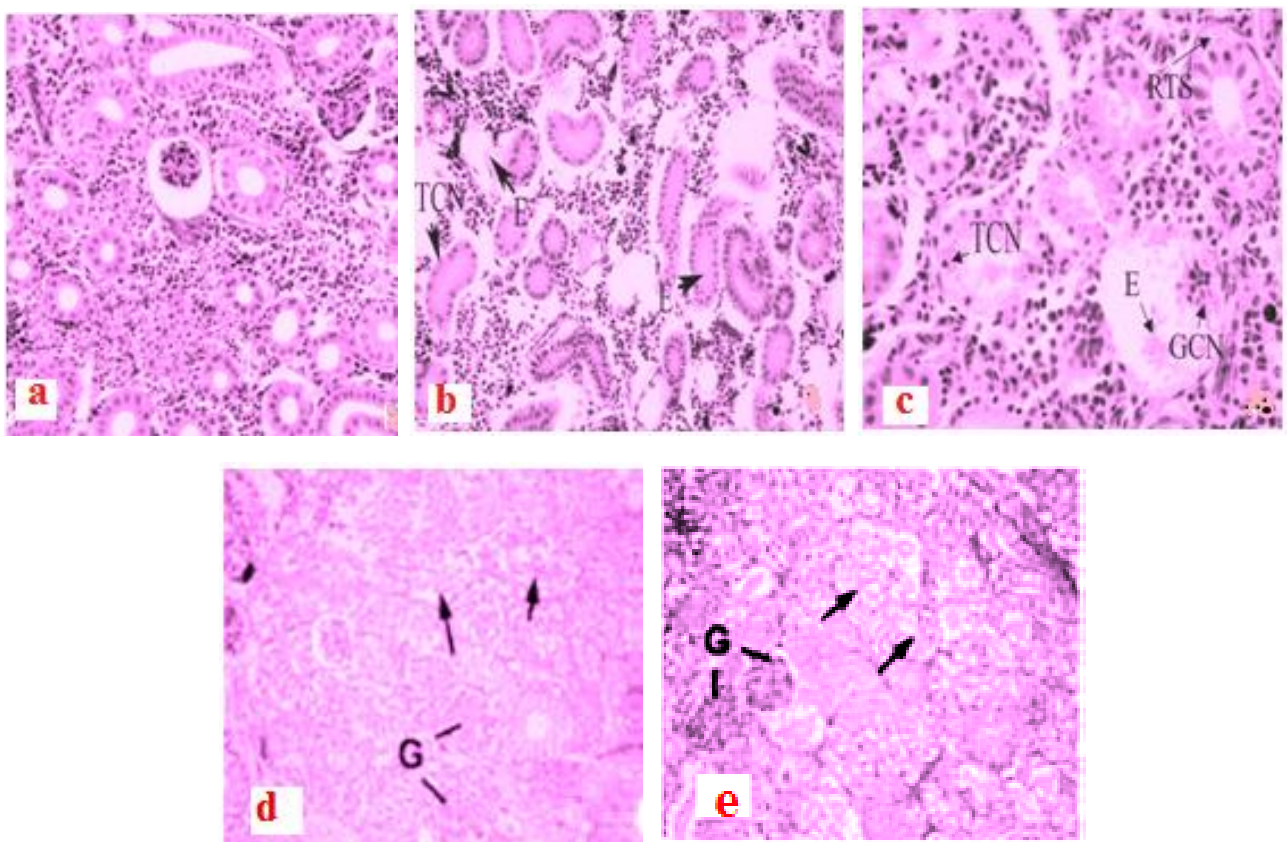

Figure 4. a) Control kidney; (b to e) normal kidney showing enlarged sinusoids and decreased hematopoietic tissue, exudates, glomerular necrosis (GCN), renal tubular separation (RTS), tubular necrosis (TCN).
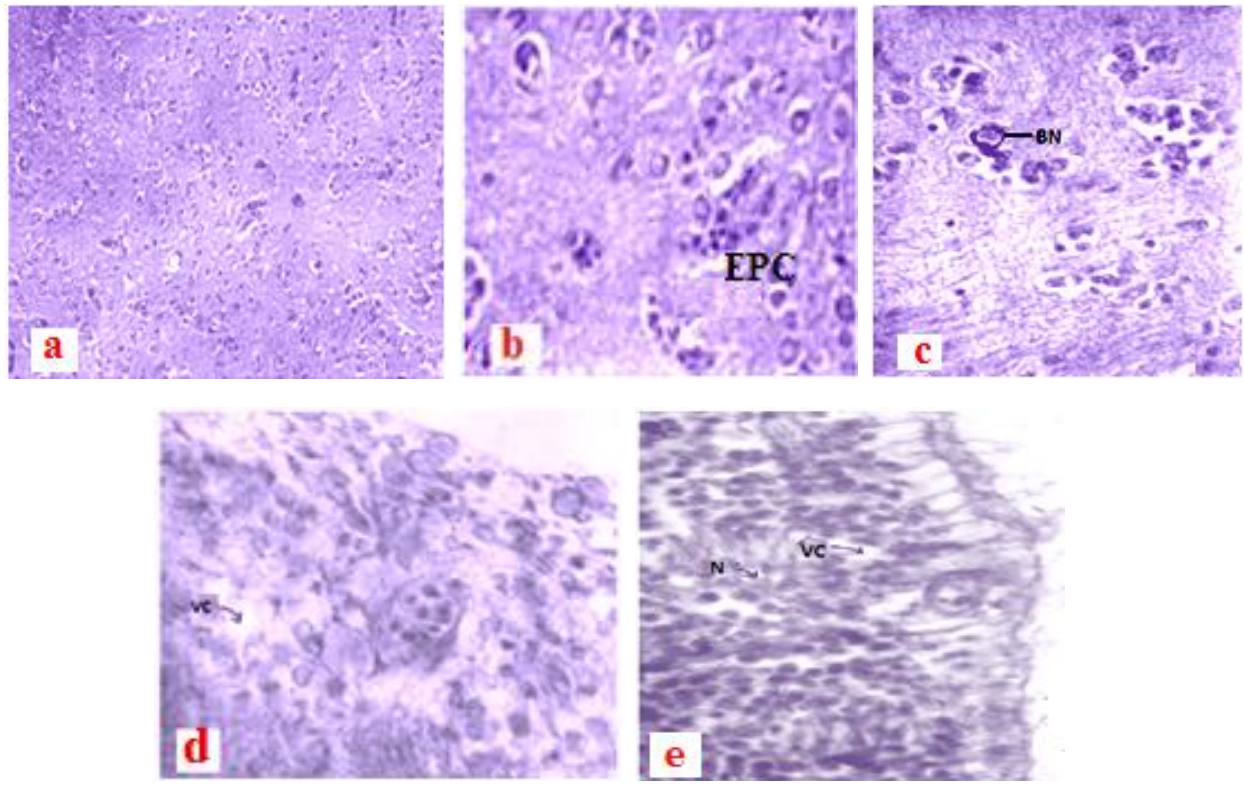

Figure 5. Brain of O. mossambicus. (a) normal; (b) enlarged pyramidal cells (EPC) at $0.8 \%$; (c) binucleated nuclei (bn) at 1\%; (d) Vacuolation (Vc) at 1.2\%; (e) necrosis $(\mathrm{N})$ at $1.4 \%$.

Thus, this study has revealed the toxicity of tannery industry wastewater on vital organs $\mathrm{O}$. mossambius. The study suggests a perfect recycling of the tannery industry wastewater before being discharged into aquatic habitat.

The environmental managers should keep a strict vigil over this discharge.

\section{ACKNOWLEDGEMENT}

The authors profusely thank University Grants Commission for providing financial assistance through Major Research Project Fellowship. Also the Management and Principal, Yadava College, Madurai deserves our sincere 
thanks for their goodwill support.

\section{REFERENCES}

Ayoola SO, Ajani EK (2008), Histopathological effects of Cypermethrin on Juvenile African Catfish (Clarias gariepinus). J. Biol. Res. 001(2):1-14.

Das BK, Mukherjee SC (2000). A histopathological study of carp (Labeo rohita) exposed to hexachlorocyclohexane. Veterinarski Arehiv. 70(4):169-180.

Ebeling G (1931). Recent results of the chemical investigation of the effect of waste water from cellulose plant on fish. Vom. Wasser 5:192-200.

Fanta E, Rios FS, Romao S, Vianna ACC, Freiberger S (2003). Histopathology of the fish Corydoras paleatus contaminated with sublethal levels of organophosphorus in water and food. Ecotoxicol. Environ. Saf. 54:119-130.

Figueiredo-Fernadens A, Ferreira-Cardoso JV, Garcia-Santos S, Monteiro SM, Carrola J, Matos P, FontaA-nhas-Fernandes A (2007). Histopathological changes in epithelium of Nile tilapia, Oreochromis niloticus, exposed to waterborne copper. Pesq. Vet. Bras. 27:103109.

Helmlata V, Srivastava N (2008). Zinc induced architectural alterations and accumulation in the ovary of fresh water teleost, Channa punctata (BLOCH). Electron. J. Ichthyol. 2:85-91.

Hewitt LM, Parrott JL, McMaster ME (2006). A decade of research on the environmental impacts of pulp and tannery mill effluents in Canada: sources and characteristics of bioactive substances. J. Toxicol. Environ Health B9(4):341-356.

Kaneko JJ (1989). Clinical Biochemistry of domestic animals. 4th ed. Diego, Academic press Inc.California, p.132.

Kelly WR (1979). Veterinary Clinical Diagnosis. 2nd ed. Balliere Tindall, London pp.266-279.

Kohler A, Wahl E, Söffker K (2002). Functional and morphological changes of lysosomes as prognostic biomarkers of toxic liver injury in flatfish, Platichthys flesus L. Environ. Toxicol. Chem. 21:2434-2444.

Loganathan K, Velmurugan B, Hongray Howrelia J, Selvanayagam M, Bharat Bhusan Patnaik (2006). Zinc induced histological changes in brain and liver of Labeo rohita. J. Environ. Biol. 27(1):107-110.

Lohner TW, Reash RJ, Willet RE, Rose VA (2001). Assessment of tolerant sunfish populations (Lepomis $s p$.) inhabiting selenium- laden coal ash effluents. Hematological and Population level assessment. Ecotoxicol. Environ. Saf. 50:203-216.

Mario S, Diniz R, Ana C. Teresa FA, Rocha-Santos P, Luisa C, Isabel $P$, Armando CD (2010). Evaluation of the sub-lethal toxicity of Bleached Kraft Pulp Mill Effluent to Carassius auratus and Dicentrarchus labrax. Springer 10(3):345-353.
Nanda P, Panigrahi S, Nanda SB, Behera SK (2002). Toxicity of tannery mill effluent to fishes. Environ. Eco. 20(2):496-498.

Olojo EAA, Olurin KB, Mbaka G, Oluwemimo AD (2005). Histopathology of the gill and liver tissues of the African catfish Clarias gariepinus exposed to lead. Afr. J. Biotechnol. 4:117-122.

Pandey S, Parvez S, Ansari RA, Ali M, Kaur M, Hayat F, Ahmad F, Raisudeen S (2008). Effects of exposure to multiple trace metals in biochemical histological and ultrastructural features of gills of a freshwater fish, Channa punctata Bloch. Chem. Biol. Interact. 174:183-192.

Pathan TS, Sonawane DL, Khillare, YK (2009) Toxicity and behavioural changes in freshwater fish Rasbora daniconus exposed to tannery mill effluent, Bot. Res. Int. 2(4):263-266.

Pugazhvendan SR, Jothi Narendiran N, Kumaran RG, Kumaran S, Alagappan KM (2009) Effect of Malathion Toxicity in the Freshwater Fish Ophiocephalus punctatus-A Histological and Histochemical Study. World J. Fish Mar. Sci. 1(3):218-224.

Rahman MZ, Hossain Z, Mellah MFA, Ahmed GU (2002): Effect of diazinon 60EC on Anabus testudineus, channa punctatus and Barbades gomonotus Naga. The ICLARM Quarterly 25:8-11.

Rajendra KM, Chouhan S, Mishra KD (1991). Toxicity of tannery mill effluent to fish, Puntius sophor. J. Tiss. Res. 1(1 and 2):41-48.

Schalm OW, Jain NC, Carrol EJ (1995). Veterinary haematology, 3rd Ed., Philadelphia, Leaard Febiger pp.15-81.

Solbe JF (1975). Fresh water in: Handbook of Ecotoxicology (Edited by Peter Calins) BlackWell Science Ltd. Osneymeed OX 20EL 68:3.

Srivastava S, Prabhakar P, Srivastava BC (2007). Toxicity and behaviour of the fish Labeo rohita and Channa punctatus exposed to pulp paper mill effluent. J. Ecotoxicol. Environ. Monit. 17(3):241-244.

Van der Oost R, Beyer J, Vermeulen NPE (2003). Fish bioaccumulation and biomarkers in environmental risk assessment: a review. Environ. Toxicol. Pharmacol. 13:57-149.

Van Horn WM (1961). Aquatic biology and the pulp and paper Industry for Air and Stream Improv; New York, N.Y. Stream improvement Tech. Bull. 251:45.

Varadaraj G, Subramanian MA (1991). Toxic effect of paper and pulp mill effluent on different parameters of bioenergetics in the fingerlings of Oreochromis mossambicus. Environ. Eco. 9(4):857-859.

Walden CC (1976). The toxicity of pulp and paper mill effluent and corresponding measurement procedures. Water Res. 10(8):639-664. 